\title{
Erratum to: Oncoplastic Breast-Conserving Surgery for Tumors Larger than 2 Centimeters: Is it Oncologically Safe? A Matched- Cohort Analysis
}

Francesca De Lorenzi, MD, PhD ${ }^{1}$, Pietro Loschi, $\mathrm{MD}^{1}$, Vincenzo Bagnardi, $\mathrm{PhD}^{2,3}$, Nicole Rotmensz, $\mathrm{MSc}^{2}$, Gabriel Hubner, $\mathrm{MD}^{1}$, Giovanni Mazzarol, $\mathrm{MD}^{4}$, Roberto Orecchia, $\mathrm{MD}^{5}$, Viviana Galimberti, $\mathrm{MD}^{6}$, Paolo Veronesi, $\mathrm{MD}^{6}$, Marco Angelo Colleoni, $\mathrm{MD}^{7}$, Antonio Toesca, $\mathrm{MD}^{6}$, Nickolas Peradze, $\mathrm{MD}^{6}$, and Rietjens Mario, MD, $\mathbf{P h D}^{1}$

${ }^{1}$ Department of Plastic and Reconstructive Surgery, European Institute of Oncology, Milan, Italy; ${ }^{2}$ Division of Epidemiology and Biostatistics, European Institute of Oncology, Milan, Italy; ${ }^{3}$ Department of Statistics and Quantitative Methods, University of Milan-Bicocca, Milan, Italy; ${ }^{4}$ Division of Pathology and Laboratory Medicine, European Institute of Oncology, Milan, Italy; ${ }^{5}$ Division of Radiotherapy, European Institute of Oncology, Milan, Italy; ${ }^{6}$ Department of Surgery, European Institute of Oncology, Milan, Italy; ${ }^{7}$ Medical Senology, European Institute of Oncology, Milan, Italy

\section{ERRATUM TO: ANN SURG ONCOL}

DOI 10.1245/S10434-016-5124-4

In the initial online publication, Nickolas Peradze's given name was incorrect. His name has been corrected in the publication as shown in this erratum.

The online version of the original article can be found under doi:10.1245/s10434-016-5124-4.

(C) Society of Surgical Oncology 2016

First Received: 3 December 2015;

Published Online: 22 February 2016

F. De Lorenzi, MD, PhD

e-mail: francesca.delorenzi@ieo.it 